\title{
ENTRE A JUDICIALIZAÇÃO E O DESCRÉDITO: A NECESSÁRIA REFORMA DO REGIMENTO INTERNO DA CÂMARA DOS DEPUTADOS
}

\author{
BETWEEN JUDICIALIZATION AND DISREGARD: THE INDISPENSABILITY OF A REGIMENTAL \\ PROCEDURE IN THE BRAZILIAN CHAMBER OF DEPUTIES REFORM
}

Arthur Paku Ottolini Balbani*

\begin{abstract}
Resumo:
A discussão acerca da crise institucional brasileira passa, essencialmente, pela carência de legitimidade e de efetividade do Poder Legislativo, cujo processo decisório, além de burocrático, não alcança sua finalidade última - a criação de políticas públicas - e nem é socialmente respaldado. Assim, no âmbito da Câmara dos Deputados, é fundamental a discussão acerca da necessidade de reforma de seu Regimento Interno, cujas atualizações pontuais são incapazes de, hodiernamente, recuperar a coesão normativa, afastando os defeitos de técnica legislativa e superando as inúmeras dificuldades vislumbradas pela práxis parlamentar.

Palavras-chave: Constituição Federal. Crise institucional. Processo Legislativo. Câmara dos Deputados. Políticas Públicas. Reforma. Regimento Interno. Regras Informais.
\end{abstract}

\begin{abstract}
:
The current discussion over the Brazilian institutional crisis is essentially marked by the lack of legitimacy and effectiveness of the Legislative Power, which decision making process is not only bureaucratic, but insufficient to reach its main function - to develop public policies -, leading it to be socially criticized. Therefore, in Brazilian Chamber of Deputies, it is fundamental to discuss the complete reformation of its Internal regimental procedure, since punctual amendments are far from being capable to recover its normative cohesion and to eliminate all the legislative technique defauts, overcoming the difficulties faced by the legislative procedure.
\end{abstract}

Keywords: Federal Constitution. Institutional Crisis. Legislative procedure. Chamber of Deputies. Public policies. Reform. Internal Procedure. Informal rules.

\footnotetext{
Graduando em Direito pela Faculdade de Direito da USP (FDUSP). Pesquisador do Observatório de Processo Legislativo e Políticas Públicas da FDUSP e do Instituto Articule. E-mail para contato: arthur. balbani@usp.br.
} 


\section{Introdução}

Nos dias atuais, o papel institucional da Câmara dos Deputados enquanto a casa dos representantes do povo é cada vez mais questionado pela opinião pública o Brasil enfrenta, como recorrentemente afirmado pelos comentaristas políticos, um momento de descrédito da política.

A discussão acerca do papel exercido pelo Legislativo Federal perpassa diretamente por elementos fundantes de uma discussão de outra natureza e que afeta o cerne da atividade legislativa. Antes de se discutir a credibilidade e o papel social de um Poder como um todo, é necessário verificar o que ocorre no seu âmbito interno, o que, para o Legislativo, implica estudar o processo legislativo.

E, de fato, parte das críticas dirigidas à Câmara dos Deputados passa pelo processo legislativo que ali ocorre, cuja condução é marcada por fatores muitas vezes antagônicos e que, contudo, precisam ser conciliados. Entretanto, é igualmente indiscutível que este fim dificilmente é alcançado quando os vícios processuais ganham projeção de destaque, deslegitimando o próprio processo e fazendo emergir questionamentos judiciais.

O presente artigo, nestes termos, pretende analisar qual o papel do Regimento Interno da Câmara dos Deputados na construção da legitimidade do processo legislativo ocorrido naquela casa e se uma reforma regimental é imperativa, diante, sobretudo, de fatores capazes de influir no devido processo legislativo.

Para atingir este objetivo, este artigo está estruturado da seguinte forma: primeiro será feita uma breve introdução acerca do processo legislativo e do papel exercido neste pelos Regimentos Internos. A seguir, será dado enfoque ao controle jurisdicional do processo legislativo e seu status excepcional, para que, finalmente, chegue-se à análise do Regimento Interno da Câmara dos Deputados e seus vícios.

\section{Processo Legislativo: noções gerais}

O primeiro passo para compreender a importância do Regimento Interno da Câmara dos Deputados (RICD) está na conceituação do processo legislativo, bem como na identificação de sua dinâmica operacional.

Assim, a fim de se delinear um panorama geral do processo legislativo brasileiro, é preciso verificar, primeiramente, como o mesmo se estrutura dentro do sistema legal.

A doutrina majoritária insere o processo legislativo como espécie do gênero "direito processual", o que se justifica por fatores que vão além da simples representação de uma sequência encadeada de procedimentos visando a atingir determinado fim. A análise do conceito de "processo legislativo", assim, é bastante esclarecedora. 
A definição estrutural de processo legislativo é encontrada em Lopes (2009, p. 14), para quem o processo legislativo é o "conjunto de procedimentos que devem ser observados pelos agentes políticos na elaboração das normas jurídicas e na estruturação das atividades legislativas". Note-se que esse conceito prioriza a acepção lógica de processo, inserindo-a no contexto do Legislativo, mas sem adentrar em elementos que permitam uma distinção mais clara com as demais espécies processuais.

Carvalho (2002, p. 64), por sua vez, propõe tese alternativa, sustentando o processo legislativo como um sistema que delibera sobre valores, extraindo deles conclusões a respeito da expectativa social de normatização e orientando a produção de políticas públicas. Este conceito representa um avanço em relação à construção lógicoestrutural antes mencionada, pois enfoca o objetivo do processo legislativo - que também é seu elemento diferenciador -, a saber, o uso do processo como meio de implementação de políticas públicas.

Unindo os aspectos supracitados, Moraes (2015, p. 671) apresenta dois conceitos possíveis para o processo legislativo, vislumbrados a partir de óticas distintas. Para o autor, o conceito sociológico de processo legislativo indica o conjunto de razões que provocam o Parlamento a desempenhar sua função legislativa. Já o conceito jurídico (técnico-estrutural) representa o conjunto de normas disciplinadas, a nível legal ou constitucional, que devem ser observadas durante a produção legislativa.

Assim, uma vez assentada a premissa acima - de que o processo legislativo é espécie do gênero "Direito Processual" -, passa-se a um segundo ponto fundamental: compreender quais as características que o tornam sui generis, a despeito de conservar pontos de tangência com o processo judicial.

Quatro princípios processuais gerais despontam como grandes exemplos dessa zona de tangência: a adequação, a economia processual, a duração razoável do processo e o devido processo.

O princípio da adequação preconiza que, na aplicação das normas ao caso concreto, é possível que o procedimento seja flexibilizado e ajustado às especificidades do caso concreto, com fins a facilitar o desenrolar do próprio processo. É interessante, nesse cenário, destacar o apontado por Bonicio (2016, p. 215) acerca da aplicabilidade geral deste princípio no processo judicial - e que igualmente incide sobre o processo legislativo: da mesma forma que um juiz não pode impor às partes a adequação das regras processuais, o condutor dos trabalhos legislativos e a Maioria não podem modificar as normas regimentais para favorecer o trâmite de determinado projeto, sem antes chegar a um acordo com a minoria, sob risco de violação do devido processo legislativo.

A aplicabilidade da adequação ao processo legislativo decorre da também adoção da dualidade principiológica da economia processual e da duração razoável do processo, ainda que, no caso da espécie ora tratada, este seja restringido em parte 
pela figura da obstrução. O processo legislativo deve obedecer a uma lógica de custo e benefício, não sendo excessivamente oneroso aos cofres públicos, ao mesmo tempo em que não pode ter duração ínfima, incapacitando a discussão das propostas e a publicidade dos atos.

Assim como ocorre no processo judicial, o melhor exemplo de aplicação da dualidade ora pontuada está na figura da preclusão legislativa, ou seja, a restrição da prática de determinados atos a marcos temporais especificados - a título de exemplo, destaca-se a restrição da apresentação de emendas às proposições em Plenário à fase de discussão da matéria, findando tal oportunidade processual com o início da fase de votação.

Ademais, nota-se que é característica comum do gênero a conservação e a busca pelo devido processo - o que, no processo legislativo, mostra-se um princípio nuclear. $\mathrm{O}$ excesso de regras e formalidades, ainda que o torne aparentemente lento e possa sugerir prejuízo, pela colisão com o princípio da economia processual, visa a assegurar o direito ao debate democrático e a participação social na deliberação legislativa. Visase, nesse sentido, a coibição das arbitrariedades parlamentares, observando elemento igualmente implícito no princípio da Democracia - a supremacia da maioria.

Por outro lado, em linhas gerais, e sem o intuito de esgotar a diferenciação, pode-se apontar duas diferenças principais entre o processo legislativo e o processo judicial, referentes, respectivamente, à instrumentalidade das formas e à imparcialidade.

Em primeiro lugar, não se aplica a instrumentalidade das formas no processo legislativo, ainda que tal princípio seja de uso consagrado no Processo Judicial (como se depreende dos arts. 188 e 277 do $\mathrm{CPC}^{1}$ ), o que se justifica amplamente pela previsão expressa na Constituição Federal de todo um regramento geral para o processo legislativo.

Esta maior rigidez do processo legislativo encontra amparo na proteção especial dada pelo Texto Magno ao devido processo legislativo. Ocorre que, no processo legislativo, tal princípio se assenta no intuito de resguardar o direito das minorias, o qual, em regra, é alcançado mediante a observância estrita das normas processuais: não se olvide que, na dinâmica dos trabalhos legislativos, como já mencionado, presume-se a existência de uma Maioria representante dos interesses da maior parte dos cidadãos.

Nesta linha de pensamento, é de mesma relevância a inexistência de imparcialidade no processo legislativo. Se é elemento fundante do processo judicial a condução deste de maneira isenta, é justamente o oposto que caracteriza o processo

1 Art. 188. Os atos e os termos processuais independem de forma determinada, salvo quando a lei expressamente a exigir, considerando-se válidos os que, realizados de outro modo, the preencham a finalidade essencial. Art. 277. Quando a lei prescrever determinada forma, o juiz considerará válido o ato se, realizado de outro modo, lhe alcançar a finalidade. 
legislativo. São os legisladores representantes da sociedade e, ao menos em tese, têm eles o dever de representar os interesses dos grupos que os elegeram, respeitando as bandeiras de sua agremiação partidária.

$\mathrm{E}$, ante todos estes elementos teóricos, os ensinamentos de Cintra, Grinover e Dinamarco (2015, p. 68) evidenciam a classificação ora proposta para o processo legislativo enquanto espécie do gênero "Direito Processual". Isto porque os mesmos vislumbram o processo não apenas como um instrumento técnico a serviço da ordem jurídica, mas como um meio assecuratório de justiça - seja ela pela via judicial ordinária ou, como ocorre com o processo legislativo, por meio da produção normativa e da efetivação de novas políticas públicas.

2.1. O papel do Regimento Interno da Câmara dos Deputados na ordenação do processo legislativo

Ainda que a Constituição Federal preveja, nos seus arts. 59 a 70, normas gerais de regência do processo legislativo, é fato que elas não são suficientes para disciplinar completamente a dinâmica operacional do Legislativo. Entretanto, destas normas processuais constitucionais é derivado o restante do processo legislativo essencialmente regimental -, ficando, portanto, a cargo do legislador, o trato específico de questões procedimentais por meio dos regimentos internos.

O Regimento Interno da Câmara dos Deputados, nesse cenário, desempenha importante função na estruturação e organização do processo legislativo federal, pois representativo da dinâmica operacional dos trabalhos de uma das casas do Congresso Nacional, servindo, ademais, como fonte de inspiração para os regimentos internos de outras casas legislativas estaduais e municipais.

E acerca deste balizamento constitucional mencionado, é inegável que os princípios do processo legislativo - analisados em parte no item anterior - atuam na condução de parâmetros interpretativos para o texto regimental e, ademais, regem aquilo que idealmente deveriam indicar as normas regimentais. Deve ser observado, contudo, que a própria adoção destes parâmetros reflete uma opção política do legislador.

Ao redigir parecer que culminou, posteriormente, com a aprovação do texto original do Regimento, o deputado Maurício Campos (PFL/MG) apontou que a finalidade primordial do mesmo seria o aperfeiçoamento e modernização das normas processuais legislativas, norteando os parlamentares quanto ao novo paradigma legislativo a ser enfrentado, após a promulgação da Constituição de 1988. Asseverou, contudo, que as opções normativas adotadas no Regimento são também decorrentes de uma escolha técnico-política, evidenciando que o processo legislativo não é dotado da mesma 
imparcialidade que o processo judicial, ressaltando, assim, a base principiológica desta espécie processual (BRASIL, 1989).

Ao mesmo tempo, é fato que o Regimento Interno exerce função secundária de extrema importância, esta decorrente do princípio da democracia: assegurar à Maioria o controle do processo legislativo, como já pontuado quando da análise dos princípios. Ames (2003) pontua, nesse sentido, que a opção por positivar determinadas regras no Regimento e, da mesma forma, a escolha por uma interpretação dentre outras possíveis, são mecanismos de domínio da condução dos trabalhos legislativos pela Maioria. Contudo, não se pode ignorar que esse domínio não pode transgredir o devido processo legislativo, sob pena de ruína de fundamento essencial da lógica processual: é, por assim dizer, um domínio respaldado na democracia e delimitado pelos direitos da minoria parlamentar.

\section{O controle jurisdicional do processo legislativo}

A inafastabilidade da jurisdição - consagrada no art. 5\%, XXXV, da Constituição Federal ${ }^{2}$ - é fundamento do Estado Democrático de Direito e assegura a todos a competência do Poder Judiciário para apreciar, de forma indiscriminada, lesões e ameaças a direitos, sejam eles individuais ou coletivos.

Contudo, é fato que tal princípio é excepcionado em matéria de processo legislativo no que toca aos atos interna corporis, na medida em que, em virtude da Separação dos Poderes e da necessidade de se conservar a harmonia decorrente deste princípio, são restritas as hipóteses de intervenção jurisdicional sobre os atos do Legislativo.

Em resumo, como bem pontuado por Macedo (2007, p. 150), a atuação jurisdicional sobre o processo legislativo deve limitar-se às hipóteses em que há violação de regras processuais constitucionais e à defesa de direito subjetivo, observada, contudo, a liberdade das Casas Legislativas de editar seus regimentos internos - em consonância com a Separação dos Poderes - e, sobretudo, a discricionariedade dos representantes do Legislativo em interpretar e aplicar as normas regimentais, dentro dos parâmetros estabelecidos pela Carta Magna.

Essa teoria é, ademais, encampada pacificamente pela jurisprudência dos Tribunais Superiores, tendo como leading case (caso paradigma) o julgamento do Mandado de Segurança n. 20.247, cujo voto vencedor, de lavra do Ministro Moreira Alves, fixou entendimento no sentido de que os atos interna corporis são intangíveis, cabendo

\footnotetext{
2 Art. $5^{\circ}$. Todos são iguais perante a lei, sem distinção de qualquer natureza, garantindo-se aos brasileiros e aos estrangeiros residentes no País a inviolabilidade do direito à vida, à liberdade, à igualdade, à segurança e à propriedade, nos termos seguintes:

XXXV - a lei não excluirá da apreciação do Poder Judiciário lesão ou ameaça a direito;
} 
apenas ao Legislativo deliberar sobre questões que discutam observação ou interpretação das normas regimentais.

Deste modo, o controle jurisdicional do processo legislativo não é inteiramente proibido, na medida em que se admite a apreciação, pelo Poder Judiciário, do aspecto formal do processo legislativo constitucional. Entretanto, por constituírem matéria interna corporis, a apreciação do processo legislativo puramente regimental e o exame de mérito de tais atos internos se encontrariam dentro da referida zona de intangibilidade, a margem de apreciação judicial.

Posteriormente, no julgamento do Mandado de Segurança n. 24.642, o Supremo Tribunal Federal, reafirmando a sua jurisprudência, deu melhor delineamento a estas situações de excepcionalidade à vedação de apreciação dos atos internos do Legislativo, estabelecendo que o exame de mérito de tais atos seria possível se, e apenas se, violada explicitamente norma constitucional. Deste modo, a Corte dirimiu quaisquer questionamentos acerca da possibilidade de intervenção judicial quando houver apenas suposta - e genérica - violação da ordem constitucional.

Assim, tanto a doutrina constitucional quanto a jurisprudência mantêm, nos dias de hoje, posição majoritária em favor da intangibilidade dos atos interna corporis, observadas as limitações acima abordadas.

Convém pontuar, contudo, que a redação final da proposição que originou a Lei n. 9.882/1997 - regulamentadora da Ação de Descumprimento de Preceito Fundamental - previa hipótese de controle de constitucionalidade nos casos de ofensa das normas regimentais ou de interpretação divergente dessas normas para o processo legislativo das espécies normativas do art. 59 da Constituição - especificamente, o art. $1^{\circ}$, parágrafo único, II, o art. $5^{\circ}, \S 4^{\circ}$, e o art. $9^{\circ}$, todos posteriormente vetados.

Em sua justificativa para a criação da norma, a autora do projeto, Sandra Starling, apontou que os parlamentares deveriam, observado o número mínimo de um décimo do total de membros da casa como signatários, ter o direito de impetrar reclamações junto ao STF, com fins a regular os atos interna corporis do Poder Legislativo atinentes às regras processuais, o que, ao ver da deputada, asseguraria a economia processual e o respeito da própria Constituição Federal.

No entanto, o projeto terminou por ser vetado pelo Executivo, pelo entendimento de que haveria violação do princípio da separação de Poderes nesse ato, pela incursão indevida do Judiciário em matérias internas do Poder Legislativo - baseandose, para tal, em decisões pretéritas do próprio STF, assentando a premissa da Separação de Poderes para afastar a intervenção excessiva da jurisdição constitucional no processo legislativo (BRASIL, 1999). 
4. A necessidade de reforma do Regimento Interno da Câmara dos Deputados

A mudança do quadro constitucional do processo legislativo brasileiro ocorrida ao longo dos últimos trinta anos - em virtude, sobretudo, da proliferação de emendas constitucionais, inclusive em matéria de processo legislativo - e da própria mudança de expectativas da sociedade em relação ao Congresso Nacional evidencia o surgimento de uma nova realidade fática que, contudo, não é observada pelo Legislador, traduzindo-se em mudanças regimentais de forma extremamente morosa.

Pode-se, em verdade, equiparar a reforma do Regimento Interno de qualquer órgão como um momento de ruptura com a ordem anterior - e isto não deixa de ser verdade no referente à Câmara dos Deputados - que, contudo, é necessária para, em muitas vezes, reafirmar a sua legitimidade e assegurar a eficácia dos meios adotados para alcançar um objetivo. No processo legislativo - especialmente no âmbito do RICD.

$\mathrm{E}$, de fato, verifica-se de forma sólida na doutrina que proliferam as críticas ao processo legislativo, sobretudo em decorrência de sua burocratização excessiva atentando, assim, contra o princípio da economia processual - e da própria inobservância de diversas regras regimentais e processuais pelos atores controladores do poder decisório do Legislativo, que utilizam de artifícios diversos para impor uma determinada orientação interpretativa do texto regimental.

Lutaif (2018, p. 426), ao analisar o processo legislativo em matéria educacional, identificou que grande parte dos projetos de lei referentes a educação deixam de ser apreciados por conta de um dispêndio excessivo de tempo e pela priorização de pautas de interesse parlamentar, ainda que haja demanda popular pela aprovação desses projetos. Nota-se, assim, neste singelo exemplo, um claro descompasso promovido pela forma como atualmente se estrutura o processo legislativo, pois pautas de pouca relevância popular podem se sobrepor a outras de grande interesse e impacto social.

Neste sentido, é evidente que a existência de falhas e/ou vícios no Regimento Interno é fator impactante na legitimidade e na eficiência do processo legislativo.

Assim, no presente item, longe de se pretender esgotar todos os aspectos que ensejariam modificações no Regimento Interno, objetiva-se a indicar aquelas mudanças que seriam as principais, dada a sua relevância dentro da ordem processual legislativa.

Isto posto, convém destacar a existência de dois tipos de situações ensejadoras de revisão do texto regimental, ressaltando, desde logo, que ambas serão analisadas em detalhes mais adiante. São elas as incongruências - meros defeitos de técnica legislativa, exemplificativamente, incoerências normativas, lacunas e ambiguidades - e as inconstitucionalidades, estas decorrente essencialmente da ausência de um processo mais apurado de adequação entre Constituição Federal e Regimento Interno, em face da edição de quase uma centena de Emendas Constitucionais nos últimos trinta anos. 
Por fim, convém fazer breve esclarecimento acerca da necessidade da reforma do Regimento Interno da Câmara dos Deputados. Uma vez que há entendimento pacífico no Supremo Tribunal Federal a respeito da impossibilidade de apreciação judicial dos atos interna corporis, salvo quando estes forem manifestamente inconstitucionais como já mencionado no item anterior -, é insuficiente a mera provocação do Judiciário para solução destas controvérsias, sob o risco de prática de ativismo judicial e, inclusive, de violação à Separação dos Poderes.

\subsection{Defeitos de técnica legislativa no Regimento Interno da Câmara dos Deputados}

Nos termos da metodologia anteriormente apresentada, os defeitos de técnica legislativa - ou, de forma geral, problemas hermenêuticos - se subclassificam em ambiguidades, incoerências normativas e lacunas, consoante terminologia adotada por Mendes e Branco (2015, p. 91).

Em linhas gerais, as ambiguidades consistem na pluralidade de significados possíveis para uma mesma palavra ou conjunto de palavras, demandando, do aplicador do direito, esforço interpretativo para aplicação da norma sem desvirtuá-la daquilo que originalmente se pleiteou.

As incoerências normativas, por sua vez, representam as antinomias internas de determinado texto normativo, decorrendo, muitas vezes, de lapso do legislador originário ou da ausência de harmonização do texto após a edição de sucessivas modificações pontuais.

Por fim, as lacunas são deficiências de completude do texto normativo, indicando o lapso do legislador ao não prever determinada situação fática no ordenamento, devendo ser observado, entretanto, a racionalidade limitada dos agentes políticos - da qual se pressupõe, destarte, que é virtualmente impossível a construção de soluções harmoniosas pelas normas jurídicas para todas as situações fáticas sujeitas à incidência de tais comandos legais.

Feitas estas considerações iniciais, é possível adentrar à análise de alguns dos defeitos de técnica legislativa vislumbrados no Regimento Interno da Câmara dos Deputados, selecionados em virtude de sua relevância prática e do impacto efetivo que podem provocar nos trabalhos legislativos.

A primeira situação selecionada - e que, efetivamente, é uma das questões mais polêmicas em matéria de processo legislativo federal - toca a reeleição dos membros da Mesa Diretora em período posterior ao exercício de mandato tampão, como vislumbrado, nos últimos anos, tanto no Senado Federal (em 2008, com a possibilidade de reeleição de Garibaldi Alves Filho, não levada adiante) quanto na Câmara dos Deputados (em 2016, com a reeleição de Rodrigo Maia). 
A Constituição Federal fixa, em seu art. 57, $\S 4^{\circ}$, que, uma vez eleitos os integrantes das Mesas Diretoras das Casas do Congresso Nacional, “é vedada a recondução para o mesmo cargo na eleição imediatamente subsequente". O disposto, contudo, não indica se a regra comportaria exceções para a hipótese de um candidato que exerce mandato-tampão e busca a sua reeleição, o que certamente também não é esclarecido pela disposição regimental correlata (art. $8^{\circ}, \S 2^{\circ}$, RICD), ${ }^{3}$ igualmente silente.

O principal documento autorizador da eleição-tampão é parecer produzido pelo então advogado Luís Roberto Barroso, quando da discussão a respeito da admissibilidade da reeleição de Garibaldi Alves Filho ao cargo de Presidente do Senado. No parecer, Barroso (2008, p. 3) afirmou que existe lacuna normativa no caso da sucessão em virtude de vacância permanente, tanto constitucional como regimental, de forma que não se pode depreender da leitura do art. $57, \S 4^{\circ}$, que o parlamentar eleito em mandatotampão esteja sujeito ao impedimento da reeleição.

No entanto, também destaca Barroso que, em existindo lacuna normativa que versa sobre matéria interna corporis, deve o Supremo Tribunal Federal acatar a interpretação do Legislativo, salvo no caso de flagrante inconstitucionalidade. Como, no caso concreto, a Constituição também é dotada de lacuna, então deverá prevalecer a interpretação dada pelos parlamentares competentes.

Ainda sobre esse tema, cabe destacar que nunca houve discussão mais elaborada no STF em virtude de ser a matéria eminentemente interna corporis - e, como visto no capítulo 3 , tende o Judiciário a intervir o mínimo possível nas questões internas do Legislativo. Além disso, como não se trata de eminente violação da ordem constitucional, as chances do STF se debruçar sobre o tema para uma análise mais detalhada é praticamente nula.

Outro interessante defeito de técnica legislativa - e que atualmente se configura como um problema prático de grande monta - toca o desarquivamento de proposições na Câmara dos Deputados.

$\mathrm{O}$ art. 105 do RICD determina que, ao fim da legislatura, serão arquivadas todas as proposições em tramitação, salvo aquelas excepcionadas pelo próprio artigo. ${ }^{4} \mathrm{O}$

3 Art. $8^{\circ}$. Na composição da Mesa será assegurada, tanto quanto possível, a representação proporcional dos Partidos ou Blocos Parlamentares que participem da Câmara, os quais escolherão os respectivos candidatos aos cargos que, de acordo com o mesmo princípio, lhes caiba prover, sem prejuízo de candidaturas avulsas oriundas das mesmas bancadas, observadas as seguintes regras:

$\S 2^{\circ}$. Se até 30 de novembro do segundo ano de mandato verificar-se qualquer vaga na Mesa, será ela preenchida mediante eleição, dentro de cinco sessões, observadas as disposições do artigo precedente. Ocorrida a vacância depois dessa data, a Mesa designará um dos membros titulares para responder pelo cargo.

4 Art. 105. Finda a legislatura, arquivar-se-ão todas as proposições que no seu decurso tenham sido submetidas à deliberação da Câmara e ainda se encontrem em tramitação, bem como as que abram crédito suplementar, 
parágrafo único do referido artigo, por sua vez, abre a possibilidade de desarquivamento da proposição mediante requerimento do autor, dentro dos primeiros cento e oitenta dias da sessão legislativa ordinária subsequente.

O problema, aqui, está em uma regra informal acomodativa - ou seja, regra não positivada e que se sobrepõe à própria lógica do Regimento Interno - que se tornou recorrente na Câmara Federal: a admissibilidade da adição de novos autores à proposição durante o trâmite da mesma, com fins a possibilitar o desarquivamento de proposições quando não reeleito o autor original.

Apenas para exemplificar a situação acima, ao término da legislatura passada (2015/2018), a fim de evitar o arquivamento do PL n. 10.374/2018 - apensado ao PL n. 8.497/2017 e já tendo recebido parecer na Comissão de Educação da Câmara dos Deputados -, foi apresentado o Requerimento n. 9.340/2018 pelo autor da proposição, Otávio Leite, não reeleito, e pelo deputado reeleito Eduardo Cury, via da qual este foi nomeado coautor da proposição em questão.

Veja-se que, ainda que não haja vedação explícita no art. 102 do Regimento Interno à nomeação posterior de coautor, causa no mínimo perplexidade a relativa ilogicidade do procedimento - pois se pressupõe a existência de coautor desde o momento de concepção da proposição. Ademais, após a sua distribuição, é fato que pouco importará, para efeitos práticos que não o eventual desarquivamento, a pluralidade de autores.

E tal situação, caso venha se tornar regra, pode acarretar em grande problema de ordem prática, na medida em que há o risco de um dos relatores da proposição vir a se tornar coautor posteriormente, provocando a confusão entre ambas as funções e violando o art. 43 do RICD. ${ }^{5}$

Um terceiro defeito de técnica legislativa - e que possui impactos diretos na economia processual - é a ausência de maiores restrições para o instituto da urgência legislativa - decorrente, sobretudo, da redação do art. 153 , IV, do texto regimental. ${ }^{6}$

Ocorre que, ainda que o intuito deste instituto fosse adequado - pois asseguraria a celeridade processual necessária para matérias relevantes e cuja aprovação

com pareceres ou sem eles, salvo as: I - com pareceres favoráveis de todas as Comissões; II - já aprovadas em turno único, em primeiro ou segundo turno; III - que tenham tramitado pelo Senado, ou dele originárias; IV - de iniciativa popular; V - de iniciativa de outro Poder ou do Procurador-Geral da República.

5 Art. 43. Nenhum Deputado poderá presidir reunião de Comissão quando se debater ou votar matéria da qual seja Autor ou Relator. Parágrafo único. Não poderá o Autor de proposição ser dela Relator, ainda que substituto ou parcial.

6 Art. 153. A urgência poderá ser requerida quando:

I - tratar-se de matéria que envolva a defesa da sociedade democrática e das liberdades fundamentais;

II - tratar-se de providência para atender a calamidade pública;

III - visar à prorrogação de prazos legais a se findarem, ou à adoção ou alteração de lei para aplicar-se em época certa e próxima;

IV - pretender-se a apreciação da matéria na mesma sessão. 
deve se dar de forma rápida, pelo risco da mora ao seu resultado útil -, na prática, notase a aplicação indiscriminada da urgência em matérias que poderiam se submeter ao rito ordinário de votação.

E, de fato, a ausência de contornos mais restritivos no Regimento Interno abriu perigosa margem de discricionariedade aos agentes políticos, possibilitando o trâmite de matéria realmente urgente - previstas nos incisos I a III do art. 153 - em mesmo rito que matérias cuja urgência é definida pela simples conveniência.

Em decorrência desta situação calamitosa - pois impossível a apreciação de qualquer proposição que não se encontrasse em urgência -, foi necessária a interpretação do Regimento Interno de forma a excluir do sobrestamento de pauta, consequência jurídica da não apreciação das matérias em regime de urgência, aquelas matérias que não se sujeitem a tal regime de tramitação.

Assim, na resposta dada à Questão de Ordem n. 411/2009, o então Presidente da Câmara dos Deputados, Michel Temer, entendeu que, ainda que a lógica deste rito de tramitação seja incentivar o legislador a apreciar as matérias de maior relevância, é fato que há proposições sujeitas a regimes especiais de tramitação, nos quais é vedada a urgência - como as Propostas de Emenda à Constituição - e, deste modo, sobre elas não se projetariam os efeitos do sobrestamento.

Contudo, o problema não se encontra completamente solucionado, pois inexistirá preferência de votação entre as matérias consideradas urgentes nos termos do art. 153. Assim, em virtude do grande número de proposições que tramitam sob este regime, o simples fato de qualquer proposição não ser considerada urgente inviabiliza, na prática, a sua apreciação em Plenário.

Por fim, convém registrar um dos temas mais sensíveis em matéria regimental e cuja resolução poderia impactar de maneira definitiva em muitas das críticas que recaem sobre o processo legislativo na Câmara dos Deputados.

Quando da elaboração do atual Regimento Interno, em 1989, foi proposta, simultaneamente, a redação de um Regimento Interno para as Comissões, nos termos do Ato da Mesa n. 177/1989 e do art. $2^{\circ}$ da Resolução n. 17/1989, com fins a criar um procedimento legislativo específico para os órgãos fracionários, cuja dinâmica operacional difere substancialmente daquela do Plenário. Ocorre que, em virtude da possibilidade de aplicação de parte das regras gerais do RICD para as comissões, a criação de um texto especializado se tornou desinteressante, ainda que, na prática, o resultado tenha sido lesivo para o devido processo legislativo.

É inegável que a ausência de um Regimento Interno para as comissões permanentes é fator de grande prejuízo à economia processual e ao próprio processo legislativo, na medida em que demanda a adaptação substancial do texto regimental à realidade particular das comissões. 
Nesse sentido, a doutrina rotineiramente aponta a operacionalização das questões de ordem no âmbito das comissões como um dos melhores exemplos para esta dificuldade estrutural. Tanto Pacheco e Mendes (2017, p. 49) quanto Casseb (2008, p. 315) são enfáticos ao apontar que o RICD prevê, como regra geral, o cabimento de recurso contra resposta à questão de ordem para a Comissão de Constituição de Justiça, com cabimento de efeito suspensivo. A regra adaptada às comissões, contudo, transfere a competência recursal para a Presidência da Câmara dos Deputados, privando ao interessado de ver seu recurso deliberado em colegiado.

Ademais, é de se considerar que, para a deliberação das Comissões, inexistem as "súmulas de entendimento" - uniformização interpretativa do Regimento Interno -, afetando diretamente a economia processual e reduzindo a padronização das decisões tomadas. Ainda que a segurança jurídica neste tema já seja diminuta em matéria de deliberação no Plenário - pela existência de precedentes conflitantes e pelos interesses políticos que norteiam a condução dos trabalhos legislativos -, é igualmente inegável que as Comissões Permanentes possuem entendimentos conflitantes para situações análogas, os quais, por vezes, conflitam com as próprias deliberações do Plenário.

Por fim, ainda no tocante às comissões especiais, é notória a infração ao princípio da economia processual promovida pela proliferação indiscriminada de comissões especiais, nos termos do art. 34 , II, do RICD. ${ }^{7}$

Note-se que, na origem, o intuito do legislador era dinamizar o processo legislativo e, em atenção à economia processual, condensar a tramitação de proposições mais complexas em uma única comissão de mérito. Contudo, o que se vê na prática é o retardamento da tramitação por meio do uso de mecanismos protelatórios secundários, tal qual a não indicação, pelas bancadas, dos membros da Comissão: caso clássico que ilustra a situação ora exposta é a Comissão Especial destinada a apreciar o PLP n. 221/1998 (alteração da Lei Kandir), criada em 1998 e que apenas teve superada a fase de indicação de parlamentares em 2017, quase vinte anos após a sua criação.

$\mathrm{O}$ dano causado à economia processual é observado inclusive do ponto de vista estatístico, na medida em que, em vez de ser exceção, a criação de comissões especiais tem se tornado cada vez mais frequente - considerando as últimas quatro legislaturas, foram criadas 59 comissões especiais no período 2003/2007, 44 em 2007/2011, 53 em 2011/2015 e 79 no período 2015/2018.

Art. 34. As Comissões Especiais serão constituídas para dar parecer sobre: II - proposições que versarem matéria de competência de mais de três Comissões que devam pronunciar-se quanto ao mérito, por iniciativa do Presidente da Câmara, ou a requerimento de Líder ou de Presidente de Comissão interessada. 


\subsection{Inconstitucionalidades no Regimento Interno da Câmara dos Deputados}

Também é de se destacar a existência de inconstitucionalidades no texto regimental, as quais decorrem, como já mencionado quando introduzida a temática, da ausência de um trabalho constante de análise e de readequação do Regimento Interno em face da realidade constitucional.

Nesse sentido, e sem pretender esgotar a temática, dadas as limitações de tamanho deste artigo, destaca-se a mais premente situação de inconstitucionalidade do texto regimental: as disposições do art. 251, I, "b", e IV, ao determinarem a votação secreta para o processamento interno do afastamento e da licença para instauração de processo contra Deputado preso em flagrante. ${ }^{8}$

Na redação original do texto constitucional, o art. 53, $\S 3^{\circ}$, previa a hipótese de votação secreta para a apreciação do auto de prisão em flagrante do parlamentar, ato no qual a Casa Legislativa deliberaria acerca da manutenção da prisão, autorizando a formação de culpa. De forma bastante semelhante, e dentro do mesmo contexto - que se manteve até a promulgação das Emendas Constitucionais ns. 35/2001 e 76/2013 a cassação do mandato parlamentar também dependia de votação secreta até que, em virtude de forte pressão popular, originada do "Caso Natan Donadon" - episódio no qual um parlamentar condenado criminalmente e com trânsito em julgado da sentença foi mantido no cargo de Deputado Federal após votação secreta - foram editadas as Emendas supracitadas, abolindo a utilização de votação secreta nestas hipóteses.

Note-se que, enquanto este tema nunca foi trazido à tona na pauta de discussões da Câmara dos Deputados, situação análoga se deu junto ao Senado Federal, quando da prisão em flagrante do Senador Delcídio do Amaral. No caso, instalou-se grande discussão no Plenário do Senado Federal, tendo como controvérsia central a constitucionalidade do art. 291, I, “c”, do Regimento Interno9 daquela Casa Legislativa,

\footnotetext{
$8 \quad$ Art. 251. Recebida a solicitação ou os autos de flagrante, o Presidente despachará o expediente à Comissão de Constituição e Justiça e de Cidadania, observadas as seguintes normas:

I - no caso de flagrante, a Comissão resolverá preliminarmente sobre a prisão, devendo:

b) oferecer parecer prévio, facultada a palavra ao Deputado envolvido ou ao seu representante, no prazo de setenta e duas horas, sobre a manutenção ou não da prisão, propondo o projeto de resolução respectivo, que será submetido até a sessão seguinte à deliberação do Plenário, pelo voto secreto da maioria de seus membros;

IV - se, da aprovação do parecer, pelo voto secreto da maioria dos membros da Casa, resultar admitida a acusação contra o Deputado, considerar-se-á dada a licença para instauração do processo ou autorizada a formação de culpa; (Grifo nosso).

9 Art. 291. Será secreta a votação:

I - quando o Senado tiver que deliberar sobre:

c) prisão de Senador e autorização da formação de culpa, no caso de flagrante de crime inafiançável (Const., art. 53, $\S 2^{\circ}$ );
} 
que, tal qual previsto no Regimento Interno da Câmara dos Deputados, preconiza a votação secreta para a manutenção da prisão e instauração do processo.

A corrente vitoriosa, capitaneada pelo Senador Cássio Cunha Lima (BRASIL, 2015), entendeu que se a mudança promovida pela Emenda Constitucional n. 76 vedou a votação secreta para as situações mais gravosas - como a cassação do mandato parlamentar -, então, logicamente, o mesmo critério se aplicaria para as situações em que se restringe o exercício do mandato, sem tolhê-lo completamente.

E não há que se discutir acerca da correção desta posição, uma vez que o princípio da publicidade é norteador do processo legislativo e, deste modo, a previsão de voto secreto deve ser entendida como numerus clausus, tal qual almejado com a EC n. 35/2001. Assim, a manutenção de regras para votação secreta que não coadunam com o mandamento constitucional é fato viciador do processo legislativo e que, como visto anteriormente, pode ser fruto de apreciação judicial.

Nesse sentido, seria de rigor que o legislador alterasse os dispositivos apresentados, suprimindo a anomalia legislativa que hoje persiste, haja vista que as votações, tanto no âmbito da Comissão de Constituição e Justiça quanto no âmbito do Plenário, devem se dar em caráter ostensivo e público, consoante o disposto na Constituição Federal.

É relevante, também, fazer breves apontamentos acerca do poderio excessivo do Colégio de Líderes - órgão composto pelos líderes de bancada e pela presidência da Casa Legislativa - e que, na prática, é o grande centro de poder deliberativo das Casas Legislativas, na medida em que define a pauta de votações do Colegiado e delibera acerca de diversas questões administrativas.

Aponta Figueiredo (2012) que a concentração de poder na mão do Colégio de Líderes termina por afetar tanto o princípio da Democracia quanto o Devido Processo Legislativo. Explica-se: não há registro, em ata, do que ocorre na reunião do colegiado - além disso, em sendo apenas reunião administrativa, a mesma também não é aberta ao público.

Deste modo, há clara marginalização dos parlamentares, com a priorização da figura do líder, o que, em contrapartida, garante maior celeridade ao processo legislativo e possibilita a efetivação da economia processual. Entretanto, por vezes, esta pode se tornar contestável por afastar o Devido Processo: a Mesa Diretora termina por sofrer o esvaziamento de suas funções e a pauta de votações termina por ser guiada, na maioria das vezes, por itens de consenso entre os partidos. Não se garante o verdadeiro debate entre Governo e Oposição, que é mitigado em favor dessas regras informais, lesando o princípio democrático. 
5. Consequências dos defeitos de técnica legislativa no Regimento Interno da Câmara dos Deputados para o processo legislativo

Como visto, os atos e deliberações das Casas Legislativas são, em regra, intangíveis judicialmente, por se tratarem de atos interna corporis, até o momento em que projetam seus efeitos externamente - ou seja, quando se tornam normas jurídicas -, sendo as normas regimentais também insuscetíveis de apreciação judicial, salvo se contradizerem texto expresso da Constituição Federal, nos termos dos precedentes do Supremo Tribunal Federal.

A combinação da inviabilidade de apreciação judicial destas matérias com a existência dos defeitos de técnica legislativa supracitados propicia o florescimento de normas informais (ou instituições informais) - informal rules -, ou seja, mecanismos legislativos extraoficiais e não escritos.

Aguiar (2015), ao analisar o papel destas regras no processo legislativo federal, conclui que a dinâmica política pressupõe a existência destas regras, na medida em que estas regulamentam e limitam o comportamento individual através do simples compartilhamento social. Assim, as regras informais possibilitariam a adaptação do processo legislativo à realidade fática de maneira mais rápida - e, por vezes, mais eficaz - do que a alteração das normas jurídicas pela via ordinária.

A mesma tese é encampada por Ferreira Junior, Perlin e Rocha (2007), para quem o processo legislativo é permeado pela constante intersecção das regras formais - as normas processuais constitucionais e regimentais - com as informais - a práxis legislativa. E, ao ver dos autores, inexistiria melhor exemplo para essa situação que a dinâmica de repartição das presidências das Comissões Permanentes, as quais, são divididas entre os partidos de acordo com sua proporcionalidade e mediante arranjos políticos feitos na Casa Legislativa - ainda, que, a contrario sensu, o art. 39 do RICD preveja a necessidade de realização de eleição para esse cargo. ${ }^{10}$

Nino (2010, p. 289) também chega a conclusão semelhante acerca da natureza das normas informais, asseverando que as regras informais carecem de verbalização justamente porque são dedutíveis a partir da conduta dos indivíduos e grupos sociais em certas situações. Entretanto, para que utilizáveis, estas normas ensejariam a presença de "circunstâncias autorizadoras", ou seja, a inexistência de uma regra escrita efetiva que regule a situação e o alcance de um fim lícito.

\footnotetext{
10 Art. 39. As Comissões terão 1 (um) Presidente e 3 (três) Vice-Presidentes, eleitos por seus pares, com mandato até a posse dos novos componentes eleitos no ano subsequente, vedada a reeleição. $\S 3^{\circ}$ Serão observados na eleição os procedimentos estabelecidos no art. $7^{\circ}$, no que couber.
} 
Nota-se, a partir dos dois autores destacados, que a prática legislativa, em virtude de sua própria complexidade, necessita de um processo legislativo eficaz e de legitimidade incontestável. Contudo, para que este objetivo seja alcançado, é necessário que as normas regimentais se encontrem hígidas e representem meio suficiente para a busca deste fim - o que, em verdade, indica a necessidade de completude e coesão das normas regimentais. E, na prática, as regras informais atuariam como meio subsidiário para, na existência de vícios e/ou defeitos de técnica legislativa, suprir as deficiências regimentais.

A análise do legislativo estadunidense por Helmke e Levitsky (2004, p. 276), a qual é projetável para a realidade fática brasileira, revela que as regras informais podem se manifestar de quatro formas distintas, a depender da convergência ou da divergência entre as regras analisadas e a qualidade das regras formais, ou seja, se efetivas ou não.

Assim, na visão dos autores, as regras informais seriam complementares (convergem com normas formais efetivas), substitutivas (convergem com normas formais não efetivas), acomodativas (divergem de normas formais efetivas) e competitivas (divergem de normas formais não efetivas). E, em virtude da existência simultânea de normas regimentais efetivas e não efetivas, adquirem as normas informais caráter de extrema importância para o desenrolar dos trabalhos legislativos.

As normas informais complementares coexistem com as normas formais efetivas, complementando-as e/ou as reforçando, por meio do preenchimento das lacunas e facilitando os meios de execução da norma formal. É o caso dos pedidos de vista das matérias nas comissões, cuja previsão regimental não indica qual o prazo fatal, contudo, à luz do devido processo legislativo, convencionou-se pela prorrogação máxima deste prazo, coincidindo-o com o momento imediatamente anterior do início da votação da matéria.

As normas substitutivas, por sua vez, são aquelas coexistentes com normas formais não efetivas, assegurando o cumprimento do mesmo objetivo ou fim que a norma formal visa a alcançar. Como ressaltado, tal norma reflete a aplicação do Regimento Interno às Comissões Parlamentares, na inexistência de um regramento próprio para estas, a despeito de comando expresso determinando a sua criação.

Já as normas acomodativas são divergentes das normas formais efetivas, criando, ademais, incentivos para os agentes sociais desrespeitarem indiretamente as normas formais. Não há, assim, violação do texto literal da norma jurídica positivada, mas sim da essência da mesma. Vislumbra-se esta situação na possibilidade de inclusão de coautor em proposição durante a sua tramitação, com fins a evitar o arquivamento definitivo ao término da legislatura: assim, ainda que a regra originária vise a reduzir o número de proposições em tramitação, é fato que a prática legislativa encontrou mecanismo para minimizar os efeitos do arquivamento. 
Por fim, as normas informais competitivas convergem com as normas formais efetivas. Ao contrário da modalidade anteriormente mencionada, há, aqui, violação expressa da norma formal - e não apenas de seu espírito - mediante a criação de estruturas e incentivos formais que tornam insustentável a manutenção da norma formal, como ocorreu na interpretação do sobrestamento da pauta, em virtude de proposição com trâmite em regime de urgência, quando da Questão de Ordem n. 411/2009.

Ademais, é de se ressaltar que as regras informais não se resumem apenas ao amoldamento das normas regimentais à situação fática, mas também à criação de normas secundárias a partir da interpretação dada ao Regimento pela Presidência ao responder Questões de Ordem. Ainda que, na origem, tal procedimento apenas visasse a interpretar o Regimento e possibilitar sua melhor aplicação aos casos concretos, não são poucos os casos em que a deliberação da Presidência da Casa resultou na criação de norma informal.

São dois os melhores exemplos da situação acima exposta, como exposto por Rabelo-Santos (2005). O primeiro, já citado neste trabalho, foi a Questão de Ordem n. $411 / 2009$, que tornou menos rígida a sistemática regimental acerca do sobrestamento de pauta e permitiu que, para as matérias insuscetíveis de apreciação por urgência e, também, durante as sessões extraordinárias - fosse possível a flexibilização da pauta.

O segundo, igualmente polêmico, tocava a devolução liminar de proposições por vício de inconstitucionalidade, prevista no art. 137, § $1^{\circ}$, do RICD. Ao responder a Questão de Ordem 10.235/1995, o Deputado Luís Eduardo Magalhães fixou entendimento no sentido de que a devolução liminar seria possível em qualquer fase do processo legislativo, pois inexistente qualquer delimitação temporal acerca do prazo preclusivo deste ato.

Note-se que essa situação era deveras perigosa, pois praticamente restringia a importância dos pareceres da CCJ - que poderiam ser suplantados por decisão liminar do presidente da Casa - violando, ademais, a economia processual, pela anulação de inúmeros atos processuais que poderiam sanar o vício em questão, haja vista a realização de controle de constitucionalidade preventivo em diversas etapas do processo legislativo. Além disso, a devolução liminar deve ser feita apenas em casos de premente inconstitucionalidade a partir de uma primeira leitura do texto - assim, se esta não foi arguida de início pelo Presidente, então a matéria não seria evidentemente inconstitucional.

Registre-se, por fim, que posteriormente houve a revisão do precedente supracitado, quando da apreciação da Questão de Ordem n. 10.074/1999. O Presidente da Casa, Michel Temer, na ocasião, entendeu que a preclusão da devolução liminar das proposições ocorria a partir do seu encaminhamento às comissões. A justificativa dada pelo Deputado foi o fato do dispositivo regimental estar inserido no capítulo referente à fase de recebimento e distribuição das proposições, logo, a prática do ato seria somente admissível durante esta fase do processo legislativo. 
E, como demonstrado ao longo deste artigo, é constante a utilização de regras informais como meios de assegurar o resultado útil do processo legislativo - a produção de políticas públicas sem que, para isso, haja dispêndio significativo de recursos pelo Estado. Contudo, não é possível ignorar o fato de a proliferação de normas informais afetar o cerne do devido processo legislativo, pois, ao mesmo tempo que dinamizam o processo, provocam a incerteza, dada a carência de segurança jurídica acerca de seu conteúdo e aplicabilidade.

Este embate apenas reforça a necessidade de se reformar o Regimento Interno da Câmara dos Deputados a fim de adaptá-lo a uma nova realidade do processo legislativo, completamente distinta do momento de sua criação. Caso contrário, há claros riscos à credibilidade e à legitimidade do processo legislativo que ocorre naquela Casa, na medida em que se desprezará o principal mecanismo de vinculação entre o processo legislativo e as garantias fundamentais, ou seja, o devido processo legislativo.

\section{Conclusão}

A manutenção do cenário de crise política no Brasil - agravada pela crise de legitimidade do Congresso Nacional perante a sociedade brasileira - evidencia o fracasso da atual dinâmica do processo legislativo, atualmente marcada pela pluralidade de normas conflitantes e por acentuados defeitos de técnica legislativa.

Como qualquer documento jurídico, precisa o RICD estar atualizado e cumprir seu papel, que, no caso, é legitimar o processo legislativo e dar-lhe efetividade, possibilitando a criação de políticas públicas. A carência de atualização das normas regimentais, nesse sentido, e em face desse momento de crise, pode levar a um movimento de contestação à própria legitimidade e transparência das decisões tomadas por esse Poder, colocando em xeque sua credibilidade institucional.

Uma vez que o controle jurisdicional do processo legislativo é extremamente diminuto, nos termos da atual jurisprudência do Supremo Tribunal Federal - sustentada pela independência funcional dos Poderes -, para que se assegure o devido processo legislativo faz-se necessário buscar mecanismos alternativos para a supressão das carências normativas e que contaminam o processo legislativo.

Das muitas soluções possíveis - passando da simples criação de interpretação vinculante das normas regimentais e culminando com a completa reestruturação do processo legislativo - optou o legislador por adotar regras informais. Contudo, a proliferação destas tornou-se um problema, pois, ainda que visem a corrigir tais falhas processuais, é inegável que apresentam concomitantemente o efeito contrário, enfraquecendo as normas positivadas e privilegiando a práxis legislativa. 
Mediante este quadro, a reforma do Regimento Interno da Câmara dos Deputados, com fins a adequá-lo a uma nova realidade constitucional, processual e até mesmo fática, torna-se um imperativo e um mecanismo de solução da crise institucional enfrentada pelo Poder Legislativo. E, mais do que isso, é uma oportunidade para que os debates sobre as políticas públicas retomem seu lugar central no Congresso, substituindo a discussão acerca desta incessante crise do Legislativo brasileiro.

São Paulo, abril de 2019.

\section{Referências}

AGUIAR, Osmar de Oliveira. As regras informais e o processo decisório na Câmara dos Deputados. 2015. Dissertação (Mestrado) - Curso de Mestrado em Poder Legislativo, Centro de Formação, Treinamento e Aperfeiçoamento da Câmara dos Deputados (Cefor), Brasília, 2015.

AMES, Barry. Os entraves da democracia no Brasil. Rio de Janeiro: Editora FGV, 2003.

BARROSO, Luís Roberto. Parecer a respeito da admissibilidade da reeleição para a presidência do Senado Federal. Brasília, 2008. Disponível em: http://www.migalhas.com.br/arquivos/2016/11/ art20161114-05.pdf. Acesso em: 22 abr. 2018.

BONICIO, Marcelo José Magalhães. Princípios do processo no novo código de processo civil. São Paulo: Saraiva, 2016.

BRASIL. Câmara dos Deputados. Projeto de Resolução n. 54, de 1989. Dispõe sobre o Regimento Interno da Câmara dos Deputados. Diário do Congresso Nacional, Seção I, Brasília, DF, 22 fev. 1989. p. 220.

BRASIL. Presidência da República. Mensagem n. 1.807, de 3 de dezembro de 1999. Diário Oficial da União, Brasília, DF, Seção 1, 6 dez. 1999, p. 10. Disponível em: http://www.planalto.gov.br/ ccivil_03/leis/Mensagem_Veto/1999/Mv1807-99.htm.

BRASIL. Senado Federal. Notas taquigráficas da $1^{a}$ Sessão Legislativa Ordinária da $55^{a}$ Legislatura: 212 ${ }^{\text {a }}$ Sessão Deliberativa Extraordinária. Brasília, DF, nov. 2015. Disponível em: https://www25. senado.leg.br/web/atividade/notas-taquigraficas/-/notas/s/3684. Acesso em: 18 mar. 2019.

CARVALHO, Cristiano Viveiros de. Controle judicial e processo legislativo. Porto Alegre: Sergio Antonio Fabris, 2002.

CASSEB, Paulo Adib. Processo legislativo: atuação das comissões permanentes e temporárias. São Paulo: Revista dos Tribunais, 2008.

CINTRA, Antônio Carlos de Araújo; GRINOVER, Ada Pellegrini; DINAMARCO, Cândido Rangel. VIDIGAL, Luís Eulálio de Bueno. Teoria geral do processo. 31. ed., rev. e ampl. São Paulo: Malheiros, 2015. 
FERREIRA JÚNIOR, Nivaldo Adão; PERLIN, Giovana dal Bianco; ROCHA, Aldenir Brandão da. Reforma política no parlamento brasileiro: considerações a partir da rejeição política do Projeto de Lei 1.210 de 2007. E-legis, Brasília, v. 5, n. 9, p. 24-51, 2012.

FIGUEIREDO, Juliana Baldoni. O Colégio de Líderes: surgimento e evolução. E-legis, Brasília, v. 5, n. 8, p. 6-33, 2012.

HELMKE, Gretchen; LEVITSKY, Steven. Informal Institutions and Comparative Politics: A Research Agenda. Perspectives On Politics, Cambridge, v. 2, n. 4, p. 725-740, Dec. 2004.

LOPES, Fabio Almeida. Princípios do processo legislativo: uma perspectiva interdisciplinar e sistêmica. 2009. Monografia (Especialização) - Curso de Processo Legislativo, Centro de Formação, Treinamento (Cefor), da Câmara dos Deputados, Brasília, 2009.

LUTAIF, Michel Kurdoglian. O Congresso Nacional e a produção legislativa educacional: um balanço crítico. In: RANIERI, Nina Beatriz Stocco; ALVES, Angela Limongi Alvarenga (org.). Direito à educação e direitos na educação em perspectiva interdisciplinar. São Paulo: Cátedra UNESCO de Direito à Educação da Universidade de São Paulo (USP), 2018. p. 403-430.

MACEDO, Cristiane Branco. A legitimidade e a extensão do controle judicial sobre o processo legislativo no estado democrático de direito. 2007. Dissertação (Mestrado) - Faculdade de Direito, Universidade de Brasília, Brasília, 2007.

MENDES, Gilmar Ferreira; BRANCO, Paulo Gustavo Gonet. Curso de direito constitucional. 10. ed., rev. e atual. São Paulo: Saraiva, 2015.

MORAES, Alexandre de. Direito Constitucional. 31. ed. São Paulo: Atlas, 2015.

NINO, Carlos Santiago. Introdução à análise do direito. São Paulo: WMF Martins Fontes, 2010.

PACHECO, Luciana Botelho; MENDES, Paula Ramos. Questões sobre processo legislativo e regimento interno. 4. ed. Brasília: Edições Câmara, 2017.

RABELO-SANTOS, Lourimar. As questões de ordem na Câmara dos Deputados: estabilidade ou instabilidade hermenêutica? 2005. Monografia (Especialização) - Faculdade de Economia, Administração, Contabilidade e Ciência da Informação e Documentação, Universidade de Brasília, Brasília, 2005. 
